\title{
Applied Occlusion (Book/DVD Set)
}

Author(s)/Editor(s): Robert Wassell / Amar Naru /

Jimmy Steele / Francis Nohl

Publisher: Quintessence Publishing Co Ltd

Language: English

ISBN: 978-1-85097-098-9

Edition: $2 / \mathrm{e}$

Publish Year: 2015

Pages: 178, illustrated

Price: $\$ 95.00$

DOI: https://doi.org/10.25241/stomaeduj.2016.3(3-4).bookreview.1

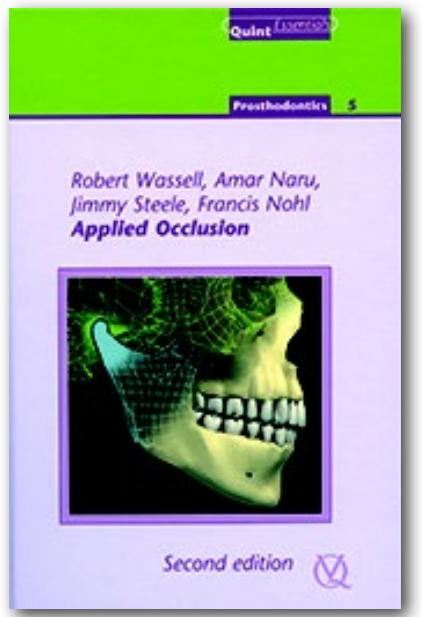

This second edition of the book entitled "Applied Occlusion" is an essential contribution highlighting how important it is for dentists and students to understand the function of the teeth. Dental occlusion is felt throughout the entire postural system and therefore any dental treatment should be done in the occlusal balance. This book is divided into eight chapters. The first two chapters present normal occlusion in static and dynamic. The following two chapters focus on the effects of deflective contacts, interferences and parafunction and demystify the reorganization of the occlusion. Chapters 5, 6 and 7 tackle considerations relating to the periodontium, implant restorations and temporomandibular disorders. The final chapter contains details about occlusal examination, intercuspal registration, articulator selection, diagnostic waxing, copying anterior guidance, occlusal splints and occlusal adjustment. The clinical videos accompanying the book narrate the process of investigating and managing occlusal problems. This book is useful for dental students, clinical dental students and dental practitioners to understand the function of the teeth, and find much better solutions for occlusal disorders.

The Books Review is drafted in the reviewer's sole wording and illustrates his opinions.

Marian-Vladimir Constantinescu $\mathrm{DDS}, \mathrm{PhD}$ ROPOSTURO - Holistic Dental Medicine Institute Bucharest, Romania e-mail: 